\title{
ABSORPTION SPECTROSCOPIC INVESTIGATION OF RHODAMINE DYE VAPORS
}

\author{
H. WEININGER, J. SCHMIDT and A. PENZKOFER \\ Viaturwissenschaftliche Fakultät II-Phvsik. Lniversität Regensburg, D-8400 Regensburg. FRG
}

Received 22 August 1988

\begin{abstract}
The dyes rhodamine $6 \mathrm{G}$ and rhodamine 19 are investigated. The dye stability versus temperature and time is studied. Bulk dye stuff is found to be less stable than dye adsorbed to the stainless steel cell walls and in the vapor phase. Rhodamine $6 \mathrm{G}$ converts to rhodamine 19 before evaporation. Adsorbed rhodamine 19 and rhodamine 19 vapor disintegrate most likely into 2,7-dimethylrhodamine 110 at elevated temperatures $\left(>320^{\circ} \mathrm{C}\right.$ ). For thodamine 19 vapor the absorption spectrum. the saturated vapor density and the latent heat of evaporation are determined. The vapor absorption spectra of rhodamine 19 and 2.7-dimethylrhodamine 110 are compared with solution spectra.
\end{abstract}

\section{Introduction}

The spectroscopic behavior of many non-ionic dyes in the vapor phase has been studied in the past [17]. For some of these dye vapors laser action was achieved [1-5] and nonlinear optical light generation was studied $[8,9]$. The spectroscopic study of ionic dyes is scarce $[10,11]$ because their vapor pressure is low and the chemical stability in the vapor phase is weak $[4,12,13]$. The evaporation of ionic dyes in an ultrasonic molecular jet was reported [13].

In this paper the evaporation of rhodamine $6 \mathrm{G}$ and rhodamine 19 is studied. The thermal decomposition of the bulk dye stuff, of the adsorbed dye at the stainless steel cell walls, and of the dye vapor is investigated. Rhodamine $6 \mathrm{G}$ is found to distintegrate into rhodamine 19 before evaporation. The unprotonated (neutral) form of rhodamine 19 is thought to exist in the vapor phase up to approximately $320^{\circ} \mathrm{C}$. Above this temperature rhodamine 19 most likely decomposes to 2,7-dimethylrhodamine 110 (2[6-amino-3-imino-2,7-dimethyl-3H-xanthen-9-yl] benzoic acid). The $S_{0}-S_{1}$ absorption spectra of rhodamine 19 vapor and of 2,7-dimethylrhodamine 110 vapor are compared with the liquid solution spectra of rhodamine 19 and rhodamine 110 , respectively. The saturated vapor density and the saturated vapor pressure of rhodamine 19 versus temperature are de- termined by measuring the dye flow through a small orifice.

\section{Experimental}

The experimental setup for the measurement of the absorption spectra of the rhodamine vapors in the visible spectral region is depicted in fig. 1a. The light of a $200 \mathrm{~W}$ tungsten lamp is collimated and passes three times through the dye vapor cell. The spectral distribution of the transmitted light is measured with a SIT vidicon (OSA of BuM Spectronic) behind a spectrometer. The vapor cell is evacuated before heating. The measurements are carried out without buffer gas. The temperature of the dye reservoir, $\vartheta_{R}$, is kept approximately $20^{\circ}$ below the temperature of the vapor cell, $\vartheta_{C}$. The cell windows (sapphire) and the high-temperature valve VI are heated separately.

The ultraviolet spectrum of the dye vapor is measured with a $5 \mathrm{~cm}$ long vapor cell (stainless steel walls with sapphire windows) in a spectrophotometer (Beckman type ACTA M4). This experimental setup is described in ref. [7].

The temperature dependence of the saturated vapor pressure (saturated vapor density) of rhodamine 19 is analysed with the arrangement of fig. $1 \mathrm{~b}$. The dye is filled in the vessel $\mathrm{Cl}$ and the vapor flow through valve $\mathrm{V} 3$ is measured at a fixed temperature 


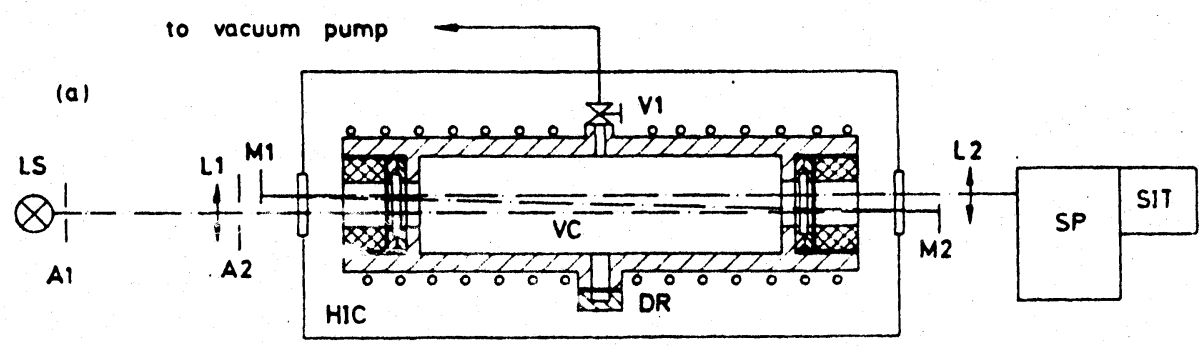

to vacuum pump

(b)

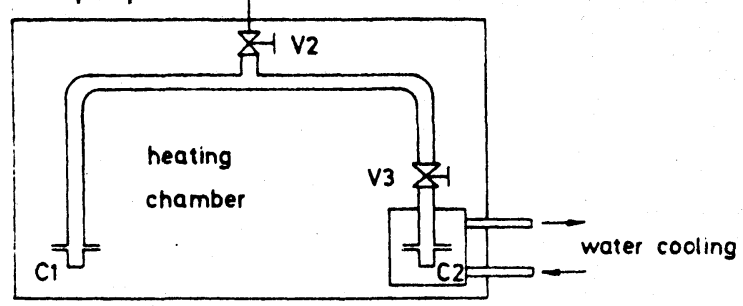

Fig. 1. (a) Experimental setup for absorption spectroscopic measurements. LS, $200 \mathrm{~W}$ tungsten lamp. A1. A2. apertures. L1, L2. lenses. M1, M2. plane mirrors. HIC, heat-insulation chamber with quartz glass windows. VC. heated vapor cell with dye reservoir DR (material is stainless steel No. 4301 consisting of $0.5 \% \mathrm{C}, 18 \% \mathrm{Cr}$, and $9 \% \mathrm{Ni}$ ), high-temperature valve $\mathrm{V} 1$ (Nupro type SS-4H-TW) and sapphire windows ( $30 \mathrm{~mm}$ diameter, $5 \mathrm{~mm}$ thickness). Cell is heated with metal-cover heating cable (approximately $1500 \mathrm{~W}$ power). The sapphire windows are heated separately (two hatched metal blocks with heating cartridges of approximately $400 \mathrm{~W}$ power consumption. each). The valve $V 1$ is heated with a glass-silk heating cable ( $300 \mathrm{~W}$ power). SP. $25 \mathrm{~cm}$ grating spectrometer. SIT, silicon intensified target vidicon of optical spectrum analyser. (b) Apparatus for dye decomposition and relative saturated vapor density measurement by accumulated dye-flow technique. C1. dye reservoir, C2. cooled vessel for condensed dye. V2, V3, high-lemperature valves. Material of apperatus is stainless steel.

(dye condensates in cooled vessel $\mathrm{C} 2$ during a fixed period of time, the amount of condensated dye is determined spectroscopically by dissolving the dye in methanol and measuring the absorption).

The arrangement of fig. $1 \mathrm{~b}$ is also used to study the thermal decomposition of bulk rhodamine $6 \mathrm{G}$ and rhodamine 19 (valve $\mathrm{V} 3$ remains closed during whole analysis). The dye is filled in vessel $\mathrm{Cl}$. Before heating up the tubing is evacuated. The time period of heating and the temperature are varied. After the heat treatment the dye is dissolved in methanol and the absorption spectrum of the dye is measured.

The thermal stability of the dye vapors is seen by inspection of the vapor absorption spectra. The dye adsorbed to the stainless steel walls of the transmission cell is analysed at the end of each measurement by cleaning the walls with methanol and measuring the absorption spectra of the solutions.

\section{Results}

\subsection{Thermal dye decomposition}

The structural formula of rhodamine $6 \mathrm{G}$ is given in fig. 2 by (1). Rhodamine $6 \mathrm{G}$ exists only in salt form. Rhodamine 19 has three forms [14]: In acid solvents (e.g. methanol with $\mathrm{HCl}$ ) the protic form (III) is present. In basic solvents (e.g. methanol with $\mathrm{NaOH}$ ) the neutral zwitterionic form (IV) exists. The neutral lactonic molecule (V) is formed in unpolar basic solvents (e.g. 1,2-dichloroethane with triethylainlune [15]) $[: 6]$. Dye dilution in neutral polar solvents (e.g. methanol) shifts the equilibrium from the protonated (III) to the unprotonated (IV) form.

The thermal stability of bulk rhodamine $6 \mathrm{G}$ is illustrated by the dashed lines in fig. 3 . Up to $200^{\circ} \mathrm{C}$ the dye remains practically unchanged by heating (experimental arrangement of fig. $\mathrm{lb}$, valve $\mathrm{V} 3$ closed). At $250^{\circ} \mathrm{C}$ rhodamine $6 \mathrm{G}$ disintegrates into rhodamine 19 within $1 \mathrm{~h}$ (absorption spectrum has the same shape as for rhodamine 19, thin film silica 

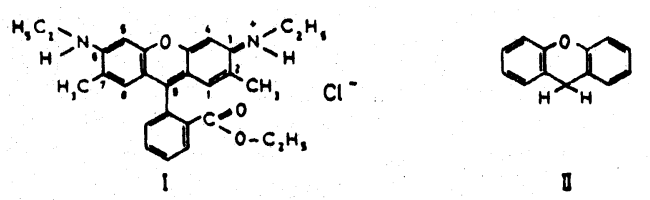

$\underbrace{H_{1} C_{2}-N_{O H}}_{\text {III }}$

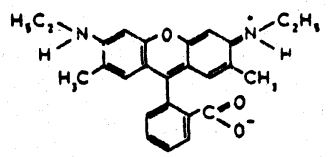

II

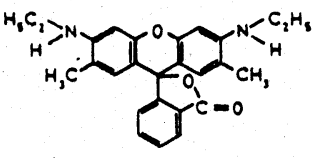

$\mathbf{Y}$

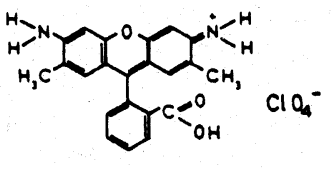

עI

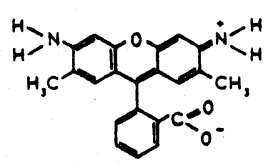

III

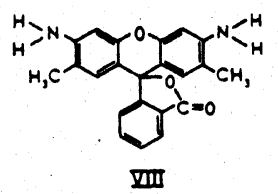

Fig. 2. Structural formulae of investigated dyes. (I) Rhodamine $6 \mathrm{G}$ chlorid, (II) xanthene, (III) rhodamine 19 perchlorate, (IV) neutral zwitterionic rhodamine 19, (V) lactonic form of rhodamine 19, (VI) 2,7-dimethylrhodamine 110 perchlorate, (VII) neutral zwitterionic 2,7-dimethylrhodamine 110, (VIII) lactonic form of 2,7-dimethylrhodamine 110 .

gel 60 chromatogram with methanol fluent shows very weak rhodamine $6 \mathrm{G}$ peak and very strong rhodamine 19 peak). Even at $200^{\circ} \mathrm{C}$ in the space above the dye sample only rhodamine 19 vapor is present (experimental arrangement of fig. $1 \mathrm{~b}$, valve V3 open, spectrum of condensed dye in vessel $\mathrm{C} 2$ is measured).

The thermal stability of bulk rhodamine 19 is illustrated by the solid lines in fig. 3 . The fraction of undestroyed solid rhodamine 19 versus time is depicted for various temperatures (absorption coefficients at wavelength $\lambda_{\max }$ of peak $S_{0}-S_{1}$ absorption undestroyed rhodamine 19 are compared). Up to $250^{\circ} \mathrm{C}$ the dye is stable. At $300^{\circ} \mathrm{C}$ the solid dye disintegrates

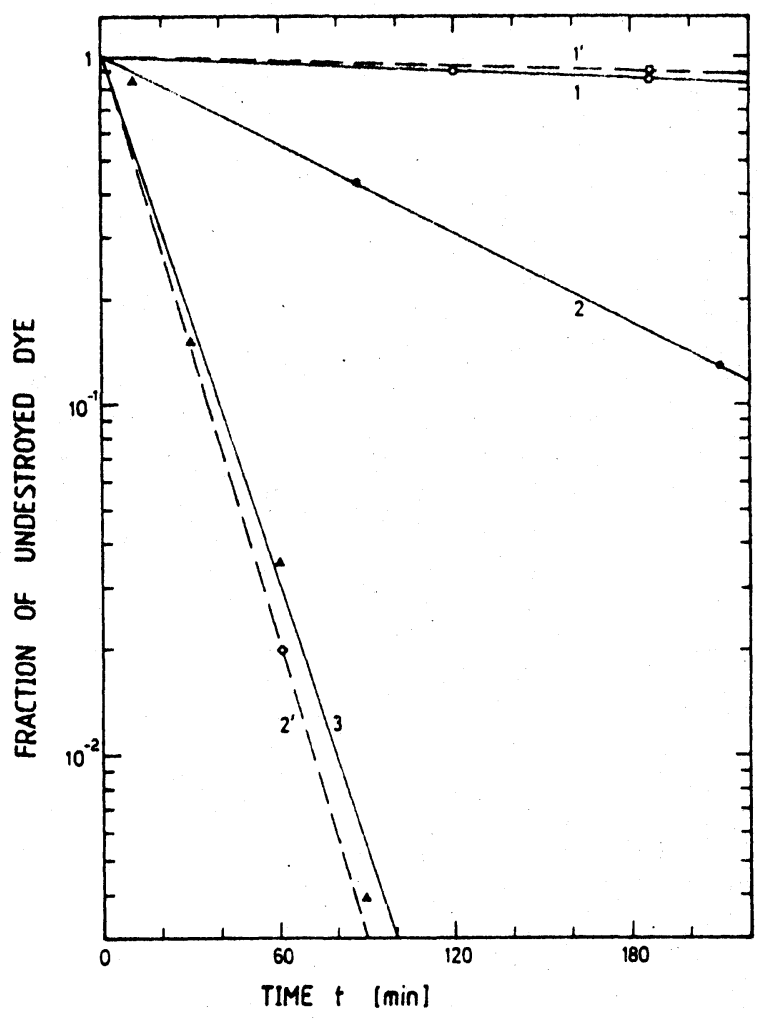

Fig. 3. Fraction of unconverted rhodamine 6G (dashed) and undestroyed rhodamine 19 (solid) versus time. Line (1). $(O)$ : $\theta=250^{\circ} \mathrm{C}$; line $(2),(\bullet): \vartheta=280^{\circ} \mathrm{C}$ : line $(3),(\Delta): \vartheta=300^{\circ} \mathrm{C}$; line $\left(1^{\prime}\right),(\square): \vartheta=200^{\circ} \mathrm{C}$; line $\left(2^{\prime}\right),(\diamond): \vartheta=250^{\circ} \mathrm{C}$.

within $1 \mathrm{~h}$. The heated bulk dye changes the absorption peak in basic methanol from $518 \mathrm{~nm}$ (neutral zwitterionic rhodamine 19 , IV) to $500 \mathrm{~nm}$ (neutral zwitterionic 2,7-dimethylrhodamine 110, VII) and carbonizes finally.

The rhodamine 19 vapor in the transmission cell is stable up to a cell temperature of $\vartheta_{C} \approx 320^{\circ} \mathrm{C}$ ( reservoir temperature $\vartheta_{R}=300^{\circ} \mathrm{C}$, transmission minimum of vapor at $\lambda \approx 500 \mathrm{~nm}$, see curve ( 3 ) of fig. $4 a)$. Above $\vartheta_{C}=320^{\circ} \mathrm{C}\left(\vartheta_{R}=300^{\circ} \mathrm{C}\right)$ the vapor disintegrates into a new dye (transmission minimum of vapor at $\lambda \approx 460 \mathrm{~nm}$, curves $(4)-(6)$ of fig. $4 \mathrm{a}$ ) which is thought to be 2,7-dimethylrhodamine 110 (VII). The rate of disintegration increases strongly with rising temperature. The dye formed newly seems to be stable up to the highest temperature applied $\left(\vartheta_{\mathrm{C}}=400^{\circ} \mathrm{C}, \vartheta_{\mathrm{R}}=380^{\circ} \mathrm{C}\right)$. The stainless steel walls catalyze probably the dye disintegration from rho- 


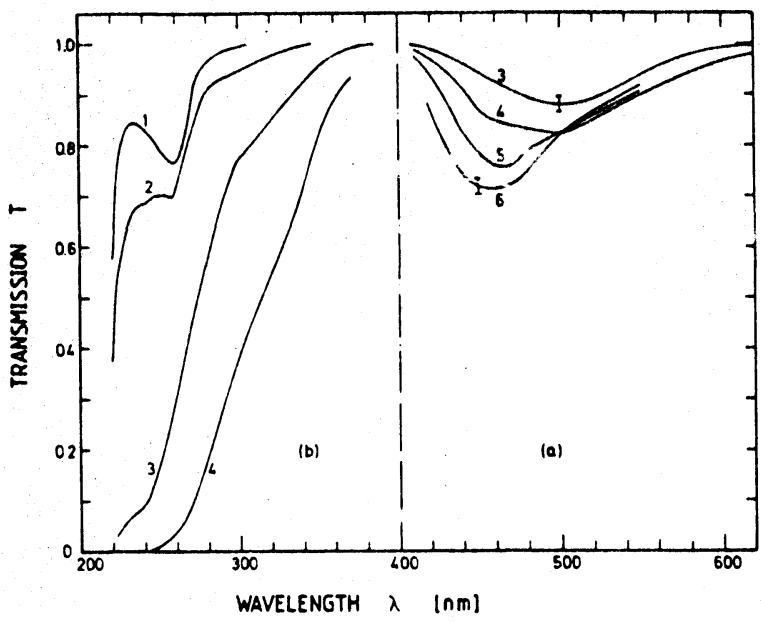

Fig. 4. Spectral transmission of vapor of heated rhodamine 19 dyestuff. (a) Visible transmission spectrum of rhodamine 19 vapor ( peak around $500 \mathrm{~nm}$ ) and of disintegrated component (peak around $460 \mathrm{~nm}$. 2.7-dimethylrhodamine 110). Triple passage through vapor cell of $42 \mathrm{~cm}$ length. (b) Ultraviolet transmission spectrum of destroyed rhodamine 19 molecules in vapor phase (probably benzene components around $260 \mathrm{~nm}$ and xanthene components around $300 \mathrm{~nm}$ ). Single passage through vapor cell of $5 \mathrm{~cm}$ length. The curves belong to: curve (1) $250^{\circ} \mathrm{C}$. curve (2) $280^{\circ} \mathrm{C}$. curve (3) $300^{\circ} \mathrm{C}$. curve (4) $320^{\circ} \mathrm{C}$. curve $(5) 360^{\circ} \mathrm{C}$, and curve (6) $380^{\circ} \mathrm{C}$. The heat-up rate is approximately $2{ }^{\circ} \mathrm{C}$ $\min ^{-1}$.

damine 19 to 2,7-dimethylrhodamine 110.

The vapor spectra (fig. $4 \mathrm{~b}$ ) indicate a strong absorption in the ultraviolet spectral region. Probably this absorption comes from dye fragments of the bulk sample like benzene, benzoic acid, xanthene (II) and xanthene derivatives. The neutral lactonic forms of rhodamine 19 (V) and of 2,7-dimethylrhodamine 110 (VIII) would absorb around $300 \mathrm{~nm}$ (see curves (3) in figs. 5 and 6 ). The presence of these forms in the vapor phase is unlikely but cannot be excluded from the vapor transmission spectra of fig. 4 .

The rhodamine 19 dye adsorbs strongly to the stainless steel cell walls. (The dye at the walls is washed out with methanol after the measurement and analysed absorption spectroscopically.) Up to a wall temperature of $\vartheta_{C} \approx 320^{\circ} \mathrm{C}$ the adsorbed dye remains mainly rhodamine 19 (acid and basic adsorption spectra correspond to spectra (1) and (2) of fig. 5). Above $\vartheta_{C}=320^{\circ} \mathrm{C}$ the dye decomposes gradually to 2.7-dimethylrhodamine 110 (acid and basic adsorption spectra correspond to spectra (1) and (2) of fig. 6 which belong to rhodamine 110 ).

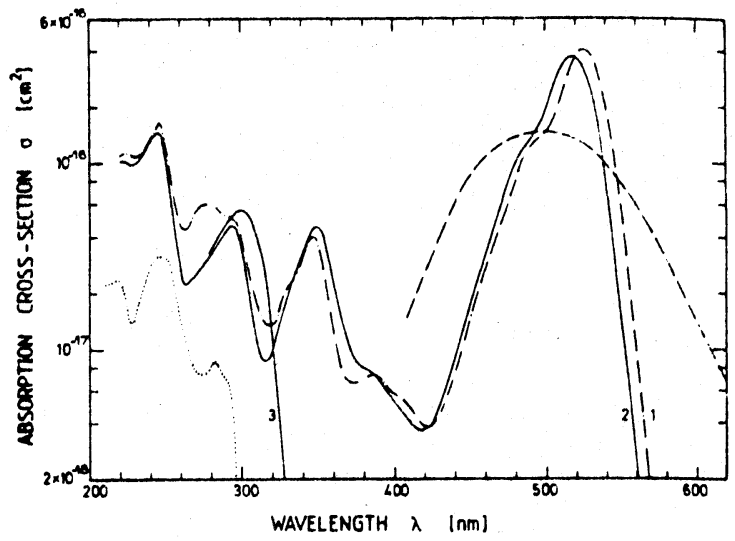

Fig. 5. Absorption cross-section spectra of rhodamine 19 in acid methanol $(+\mathrm{HCl}$, form III of fig. 2. dashed-dotted curve (1)), in basic methanol ( $+\mathrm{NaOH}$, form IV. solid curve (2)), and in basic 1.2-dichloroethane (+triethylamin. form V. solid curve (3)). The dotted curve belongs to xanthene (form II) in methanol. The dashed curve shows the absorption cross-section spectrum of rhodamine 19 vapor (form IV). The absolute values of this curve are determined by $\int_{a b s} \sigma_{v}(i) \mathrm{d} \dot{\nu}=\int_{\text {abs }} \sigma_{\mathrm{L}}(\tilde{\nu}) \mathrm{d} \dot{\nu}$ $=6.45 \times 10^{-13} \mathrm{~cm}$.

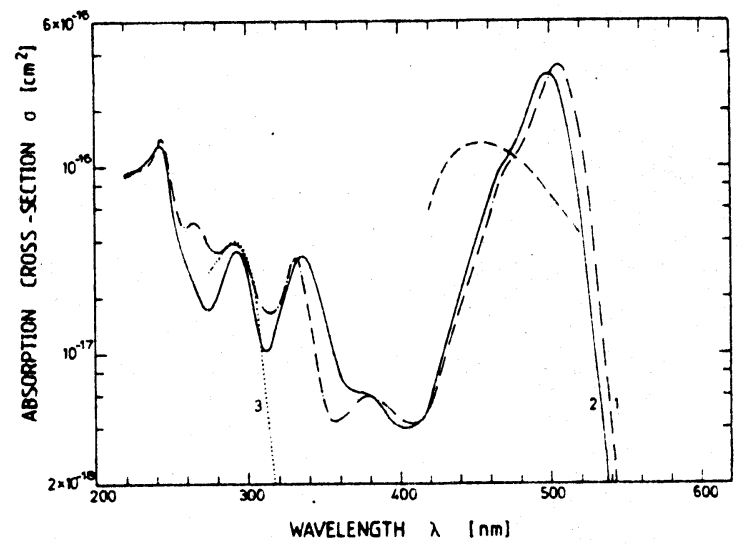

Fig. 6. Absorption cross-section spectra of rhodamine 110 in acid methanol $(+\mathrm{HCl}$, cationic form, dashed-dotted curve (1)), in basic methanol ( $+\mathrm{NaOH}$, neutral zwitterionic form, solid curve (2)) and in basic 1,2-dichloroethane ( + triethylamin. lactonic form. dotted curve (3)). The dashed curve belongs to 2,7-dimethylrhodamine 110 vapor (form VII). The absolute values of this curve are determined by $\int_{\mathrm{abs}} \sigma_{\mathrm{V}}(\bar{\nu}) \mathrm{d} \hat{i}=\int_{\mathrm{abs}} \sigma_{\mathrm{L}}(\bar{\nu}) \mathrm{d} \hat{\nu}=5.13$ $\times 10^{-13} \mathrm{~cm}$.

The lines of fig. 3 indicate that at a fixed temperature $\vartheta$ the dye disintegrates approximately exponentially according to

$N_{\mathrm{ud}}(t) \approx N_{\mathrm{ud}}(0) \exp \left[-t / \tau_{\mathrm{dis}}(\vartheta)\right]$. 
where $N_{\text {ud }}$ is the number density of undestroyed dye molecules. The disintegration time constant $\tau_{\text {dis }}$ may be approximated by an Arrhenius-type temperature dependence:

$\tau_{\mathrm{dis}} \approx \nu_{\mathrm{dis}}^{-1} \exp \left(Q_{\mathrm{dis}} / k \vartheta\right)$,

where $\nu_{\text {dis }}$ is the attempt frequency of disintegration and $Q_{\text {dis }}$ is the activation energy of disintegration. $\nu_{\text {dis }} \approx 10^{13} \mathrm{~s}^{-1}$ and $Q_{\text {dis }} \approx 3 \times 10^{-19} \mathrm{~J}$ for bulk rhodamine $19, Q_{\text {dis }} \approx 3.5 \times 10^{-19} \mathrm{~J}$ for rhodamine 19 vapor, and $Q_{\text {dis }} \approx 2.7 \times 10^{-19} \mathrm{~J}$ for bulk rhodamine $6 \mathrm{G}$ give reasonable fits.

\subsection{Absorption cross-section spectra}

As mentioned above, rhodamine $6 \mathrm{G}$ could not be transferred to the vapor phase because it disintegrated into rhodamine 19 before evaporation.

The transmission spectra obtained with rhodamine 19 in the dye reservoir are shown in fig. 4 . The spectra.in fig. $4 \mathrm{a}$ are measured with the experimental arrangement of fig. la (cell length $l=42 \mathrm{~cm}$, triple passage, i.e. total length $l_{t}=3 l$ ), while the spectra in fig. $4 \mathrm{~b}$ are measured with a $5 \mathrm{~cm}$ long vapor cell in a single passage.

The ultraviolet absorption starts already at $250^{\circ} \mathrm{C}$ (curve (1)) and increases rapidly with rising temperature (curves (2)-(4)). The UV absorption is thought to be mainly due to molecular fragments formed by the thermal destruction of the bulk dye in the reservoir.

The visible spectra (fig. 4a) belong to rhodamine molecules. Curve ( 3 ) at $\vartheta_{R}=300^{\circ} \mathrm{C}$ shows the transmission spectrum of rhodamine 19 vapor. The neutral zwitterionic form (IV) is thought to be in the vapor phase. With rising temperature (and with time) the transmission curves change over to a new spectral form which is thought to be mainly due to 2,7-dimethylrhodamine 110 (neutral zwitterionic form VII). In the experiments the heating rate was approximately $2^{\circ} \mathrm{C} \mathrm{min}^{-1}$.

The absorption cross-section spectra of rhodamine 19 vapor and of 2,7-dimethylrhodamine 110 vapor are shown by the dashed curves in figs. 5 and 6 , respectively. These spectra are derived from the transmission spectra (curves ( 3 ) and (6) of fig. 4 ) by assuming the same integral absorption cross section of the vapors and the basic methanolic solutions $[7,17,18]$, i.e.

$\int_{\text {abs }} \sigma_{\mathrm{v}}(\tilde{\nu}) \mathrm{d} \tilde{\nu}=\int_{\text {bbs }} \sigma_{\mathrm{L}}(\tilde{\nu}) \mathrm{d} \tilde{\nu}$.

The integration extends over the $S_{1}-S_{1}$ absorption region. $\sigma_{\mathrm{V}}$ and $\sigma_{\mathrm{L}}$ are the absorption cross sections of the vapors and the solutions, respectively. The absorption cross-section spectra of the protic, neutral zwitterionic, and neutral lactonic forms of the rhodamine 19 and rhodamine 110 molecules are included in figs. 5 and 6.

The wavelengths of maximum $\mathrm{S}_{0}-\mathrm{S}_{1}$ absorption of rhodamine 19 vapor and rhodamine $6 \mathrm{G}$ and rhodamine 19 in various solvents are listed in table 1. Compared to the vapor spectrum the solution spectra are shifted to longer wavelength.

The frequency shift,

$\Delta \tilde{\nu}_{\text {abs }}=\tilde{\nu}_{\text {abs, vapor }}-\tilde{\nu}_{\text {abs.sol }}$,

is related to dye and solvent parameters according to [21]

$$
\begin{aligned}
\Delta \tilde{\nu}_{\mathrm{abs}} & =J \frac{n^{2}-1}{2 n^{2}+1} \\
+ & \frac{2 \mu_{\mathrm{g}}\left(\mu_{\mathrm{g}}-\mu_{\mathrm{e}}\right)}{4 \pi \epsilon_{0} h c_{0} a^{3}}\left(\frac{D-1}{D+2}-\frac{n^{2}-1}{n^{2}+2}\right) \\
& +\frac{\mu_{\mathrm{g}}^{2}-\mu_{\mathrm{e}}^{2}}{4 \pi \epsilon_{0} h c_{0} a^{3}} \frac{n^{2}-1}{2 n^{2}+1} \\
& +K \frac{\left(D-n^{2}\right)\left(2 D+n^{2}\right)}{D\left(n^{2}+2\right)^{2}},
\end{aligned}
$$

where $J$ is a molecule-dependent constant, $\mu_{\mathrm{g}}$ and $\mu_{\mathrm{e}}$ are the permanent ground-state and excited-state dipole moments, respectively. $h$ is Planck's constant, $c_{0}$ is the vacuum light velocity, $a$ is the molecular radius, $n$ is the refractive index of the solution at $\lambda_{\text {max }}$, and $D$ is the static dielectric constant. $K$ is a constant that depends on solute and solvent parameters.

The first term of eq. (3) is due to dispersion force interaction (London forces). The other three terms are caused by electrostatic forces. The second term describes the solute dipole-solvent dipole interaction, the third term gives the interaction of the solute dipole with its induced dipole moment of the solvent (solute Stark effect). The last term gives the interaction of the solvent dipoles with the induced solute di- 
Table 1

Spectroscopic data of rhodamine 19 and rhodamine $6 \mathrm{G}$

\begin{tabular}{|c|c|c|c|c|c|c|}
\hline \multirow[t]{2}{*}{ Parameter } & \multirow[t]{2}{*}{ Vapor } & \multicolumn{5}{|l|}{ Solution } \\
\hline & & ب & methanol & chloroform & toluene & benzene \\
\hline$D$ & 1.00 & 80.08 & 33.64 & 4.8 & 2.379 & 2.284 \\
\hline \multicolumn{7}{|l|}{ rhodamine 19} \\
\hline$\lambda_{\max }\left(S_{n} \rightarrow S_{1}\right)(n m)$ & $500 \pm 10$ & $\begin{array}{l}524^{\prime \prime} \\
521^{h 1}\end{array}$ & $\begin{array}{l}\left.528^{\prime \prime}\right)[14] \\
518^{b \prime}[14]\end{array}$ & 519.5 & $528 \pm 1$ & $530 \pm 2$ \\
\hline$n\left(i_{\text {max }}\right)$ & 1.00 & $\begin{array}{l}1.3353^{\circ \prime} \\
1.3354^{n \prime}\end{array}$ & $\begin{array}{l}1.3306^{\circ 1} \\
1.3309^{\circ)}\end{array}$ & 1.4504 & 1.5026 & 1.5072 \\
\hline$\Delta \tilde{y}_{\mathrm{Abs}, \mathrm{n}}\left(\mathrm{cm}^{-1}\right)$ & 0 & $\begin{array}{l}916^{\circ 1} \\
806^{\circ 1}\end{array}$ & $\begin{array}{l}1061^{a \prime} \\
695^{b 1}\end{array}$ & 751 & 1061 & 1132 \\
\hline$\left(\mu_{8}-\mu_{\mathrm{c}}\right) / \mu_{8}{ }^{\mathrm{c}}$ & & $-2 \times 10^{-3}$ & $-1.5 \times 10^{-2}$ & $-6 \times 10^{-2}$ & 0 & 0 \\
\hline \multicolumn{7}{|l|}{ rhodamine $6 \mathrm{G}$} \\
\hline$i_{\max }\left(\mathbf{S}_{0} \rightarrow \mathbf{S}_{1}\right)(\mathrm{nm})$ & & 527 & 528 & 532.5 & 537 & 537 \\
\hline$n$ & & 1.3552 & 1.3306 & 1.4496 & 1.5016 & 1.5063 \\
\hline
\end{tabular}

"Acid solution. "Basic solution.

') Parameters used in calculation (eq. (3)) are $J=4794 \mathrm{~cm}^{-1}, K=0, \mu_{z} \approx r e=6.4 \times 10^{-29} \mathrm{C} \mathrm{m}=19.4 \mathrm{D}\left(1\right.$ debye $\left.=3.3 \times 10^{-30} \mathrm{C} \mathrm{m}\right)$, and $a=0.46 \mathrm{~nm}(r=0.4 \mathrm{~nm}$ is distance between positive and negative charge of unprotonated rhodamine 19$)$. Refractive index data are interpolated from data in refs. [19.20]. $D$ values are taken from refs. [19,20].

poles (solvent Stark effect). Eq. (3) does not include effects of hydrogen bonding and charge transfer.

The frequency shifts of the $S_{0}-S_{1}$ absorption peaks,

$\Delta \hat{\nu}_{\text {abs.p }}=\lambda_{\text {max }}^{-1}($ vap. $)-\lambda_{\max }^{-1}($ sol. $)$.

versus refractive index function $n^{2}-1$ are plotted in fig. 7 for rhodamine 19. The $n$ and $D$ values of the solvents are listed in table 1 . The curves are calculated by the use of eq. (3). The dispersion force constant $J$ is determined by remaining only the first term of eq. (3) for the solvents toluene and benzene. The ratios of dipole change $\Delta \mu / \mu_{\mathrm{g}}=\left(\mu_{\mathrm{g}}-\mu_{\mathrm{e}}\right) / \mu_{\mathrm{g}}$ for the solvents water. methanol, and chloroform are estimated by curve fitting to the experimental points while setting $K=0$ (neglect of the forth term of eq. (3) considering the solvent Stark effect ). The results are collected in table 1 . The estimated data indicate a rather small change of dipole moment by excitation to the $S_{1}$ level.

\subsection{Salurated vapor density and saturated vapor pressure}

The saturated vapor number density $N_{\mathrm{S}}$ of rhodamine 19 at $\vartheta_{R}=300^{\circ} \mathrm{C}$ is determined by the transmission curve ( 3 ) of fig. 4 and the dashed absorption cross-section curve of fig. $5\left(T=\exp \left(-\sigma_{\mathrm{V}} N_{\mathrm{S}} l_{\mathrm{l}}\right)\right]$. A value of $N_{\mathrm{S}}\left(\vartheta_{\mathrm{R}}=300^{\circ} \mathrm{C}\right)=(6.8 \pm 1) \times 10^{12} \mathrm{~cm}^{-3}$ is obtained.

The caros in fig. 8 show the saturated vapor densities of rhodamine 19 and 2,7-dimethylrhodamine 110 together. These points are determined from the transmission curves of fig. $4 \mathrm{a}$ and the vapor absorption cross sections of figs. 5 and 6 . Above $\vartheta_{R}=300^{\circ} \mathrm{C}$ the bulk rhodamine 19 in the reservoir becomes destroyed and the observed combined vapor density of rhodamine 19 and 2,7-dimethylrhodamine 110 represents the equilibrium between the dye adsorbed to the stainless steel cell walls and the dye in the vapor phase (dashed-dotted curve (a) of fig. 8). The dashed-dotted curves (b) and (c) give roughly the separated vapor density contributions of rhodamine 19 , curve (b), and 2,7-dimethylrhodamine 110, curve (c).

Below $300^{\circ} \mathrm{C}$ practically only rhodamine 19 is in the vapor phase. An absorption spectroscopic determination of the saturated vapor density of rhodamine 19 below $300^{\circ} \mathrm{C}$ is difficult because of the small absorption. Therefore the saturated vapor density of rhodamine 19 below $\vartheta_{R}=300^{\circ} \mathrm{C}$ was determined by a dye vapor flow measurement [22] (arrangement of fig. $1 \mathrm{~b}$; valve V3 half open, vessel $\mathrm{C} 2$ cooled, 


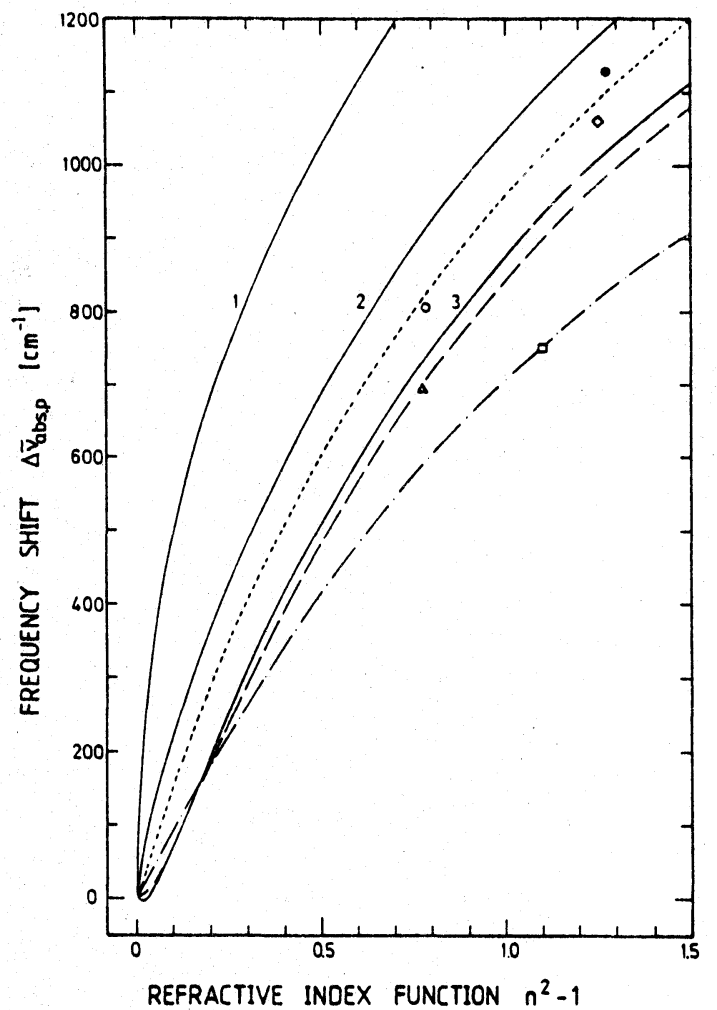

Fig. 7. Frequency shift, $\Delta \tilde{\nu}_{\text {abs. }}=\lambda_{\max }^{-1}$ (vap. $)-\lambda_{\max }^{-1}$ (sol.), versus refractive index function $n^{2}-1$ for rhodamine 19 dissolved in methanol $(\Delta)$, water $(O)$, chloroform $(\square)$, toluene $(\diamond)$, and benzene (O). Solid curves belong to $D-1=100.96\left(n^{2}-1\right)$ (water) with $\Delta \mu / \mu_{\mathrm{g}}=0.05$ curve (1), 0.01 curve ( 2 ), and -0.01 curve ( 3 ). Dashed curve, $D-1=42.32\left(n^{2}-1\right)$ and $\Delta \mu /$ $\mu_{8}=-1.5 \times 10^{-2}$ (methanol). Dashed-dotted curve, $D-1=3.44$ $\left(n^{2}-1\right)$ and $\Delta \mu / \mu_{8}=6 \times 10^{-2}$ (chloroform). Short-dashed curve, $D=0$. All curves: $J=4794 \mathrm{~cm}^{-1}$ and $K=0$.

amount of dye condensed within a fixed period of time is measured by absorption spectroscopy).

The dye flow rate through valve $\mathrm{V} 3$ is given by $[23,24]$

$n_{\mathrm{l}}=\frac{p_{\mathrm{S}}}{\left(2 \pi m k \vartheta_{\mathrm{R}}\right)^{1 / 2}}=N_{\mathrm{S}}\left(\frac{k \vartheta_{\mathrm{R}}}{-\pi m}\right)^{1 / 2}$,

where $p_{\mathrm{S}}$ is the saturated vapor pressure, $N_{\mathrm{S}}$ is the saturated vapor density, $m$ is the molecular mass, $k$ is the Boltzmann constant, and $\vartheta_{\mathrm{R}}$ is the reservoir temperature. The second equality is due to the ideal gas equation, $p_{\mathrm{S}}=N_{\mathrm{S}} k \vartheta_{\mathrm{R}}$. The amount of condensed dye is $M_{b}=\kappa_{\text {fow }} n_{\downarrow} A t m$, where $A$ is the area of the orifice of the valve, $t$ is the time period, and $\kappa_{\text {flow }}$ is a proportionality constant.

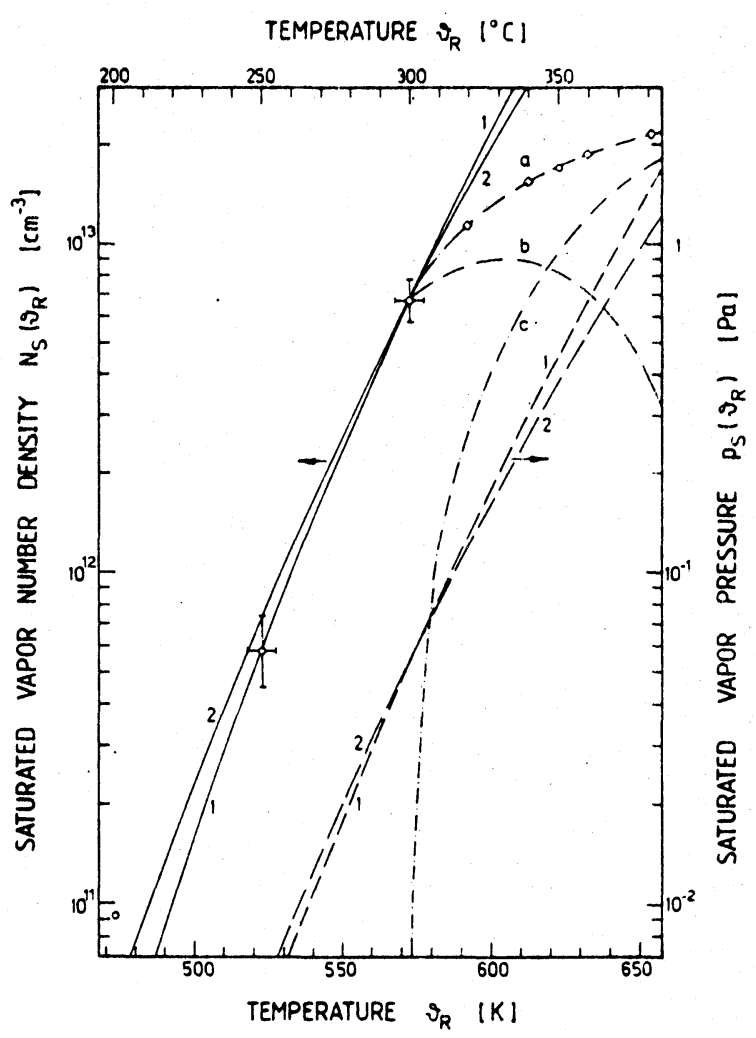

Fig. 8. Saturated vapor densities $N_{\mathrm{S}}$ (experimental points. solid and dashed-dotted curves) and saturated vapor pressures $p_{S}$ (dashed curves) versus temperature for heated rhodamine 19 dye stuff. Caros $(\diamond)$ are obtained by transmission measurements. The dashed-dotted curve (a) fits these experimental points. Circles $(O)$ are determined by dye-flow measurements. The dasheddotted curves $(b)$ and $(c)$ give roughly the contribution of rhodamine 19, curve (b), and 2,7-dimethylrhodamine 110, curve (c), to the vapor density. The solid and dashed curves are calculated (eqs. (5) and (6)) for: curve (1) $\kappa_{\text {des }}=5.56 \times 10^{8} \mathrm{~Pa}$ $\mathrm{K}^{-1 / 2}, Q_{\text {des }}=2.08 \times 10^{-14} \mathrm{~J},\left(\nu_{\text {des }} / S=3.6 \times 10^{13} \mathrm{~s}^{-1}\right)$; curve. (2) $\kappa_{\text {des }}=4.34 \times 10^{7} \quad \mathrm{~Pa} \quad K^{-1 / 2}, \quad Q_{\text {des }}=1.87 \times 10^{-19} \mathrm{~J}, \quad\left(\nu_{\text {des }}\right)$ $S=2.9 \times 10^{12} \mathrm{~s}^{-1}$ ).

The circles in fig. 8 give the experimental $N_{\mathrm{S}}$ data (calibrated at $\vartheta_{R}=300^{\circ} \mathrm{C}$ to absorption measurements ). Above $\vartheta_{\mathrm{R}}=300^{\circ} \mathrm{C}$ the rise of $N_{\mathrm{S}}$ slows down (bulk dye in reservoir destroyed, equilibrium with adsorbed dye at walls).

In cooling down the dye vapor from above $320^{\circ} \mathrm{C}$ below $300^{\circ} \mathrm{C}$ the saturated vapor pressure reduces more slowly than it rises in heating up (observed in transmission measurements, no experimental points shown in fig. 8).

The temperature dependence of the saturated va- 
por density $N_{\mathrm{S}}$ or the saturated vapor pressure $p_{\mathrm{S}}$ (eq. (4)) of rhodamine 19 vapor below $\vartheta_{R}=300^{\circ} \mathrm{C}$ allows the determination of the rhodamine 19 desorption energy $Q_{\text {des }}$ (latent heat of evaporation) [ 7,24]: The saturated vapor density is given by the dynamic equilibrium of adsorption a:d desorption. The adsorption rate is $n_{1} S$, where $S$ is lue siicking coefficient. The desorption rate is $n_{\text {surr }} \nu_{\text {des }} \exp \left(-Q_{\text {des }} / k \hat{v}_{R}\right)$, where $n_{\text {surf }}$ is the surface number density of dye molecules (dimension $\mathrm{cm}^{-2}$ ), $\nu_{\text {des }}$ is the attempt frequency of desorption (dimension $\mathrm{s}^{-1}$ ) and $Q_{\text {des }}$ is the desorption energy. The equality of adsorption and desorption rates leads to the following results

$$
\begin{aligned}
N_{\mathrm{S}} & =\left(2 \pi m / k \vartheta_{\mathrm{R}}\right)^{1 / 2}\left(\nu_{\text {des }} / S\right) \\
& \times n_{\text {surf }} \exp \left(-Q_{\text {des }} / k \vartheta_{\mathrm{R}}\right) \\
& =\kappa_{\text {des }} k^{-1} \vartheta_{\mathrm{R}}^{-1 / 2} \exp \left(-Q_{\text {des }} / k \vartheta_{\mathrm{R}}\right), \\
p_{\mathrm{S}} & =\left(2 \pi m k \vartheta_{\mathrm{R}}\right)^{1 / 2}\left(\nu_{\text {des }} / S\right) \\
& \times n_{\text {surf }} \exp \left(-Q_{\text {des }} / k \vartheta_{\mathrm{R}}\right) \\
& =\kappa_{\text {des }} \vartheta_{\mathrm{R}}^{1 / 2} \exp \left(-Q_{\text {des }} / k \vartheta_{\mathrm{R}}\right) .
\end{aligned}
$$

The calculated solid curves in fig. 8 indicate a desorption energy of $Q_{\text {des }} \approx(2.1 \pm 0.3) \times 10^{-19} \mathrm{~J}$ $=1.3 \pm 0.2 \mathrm{eV} . \kappa_{\text {des }}$ is in the range between $4 \times 10^{7}$ and $10^{9} \mathrm{~Pa} \mathrm{~K} \mathrm{~K}^{-1 / 2}$ giving $\nu_{\text {des }} / S$ values between $4 \times 10^{12}$ and $10^{14} \mathrm{~s}^{-1}\left(m=6.88 \times 10^{-25} \mathrm{~kg}\right.$, mass of neutral zwitterionic rhodamine 19, IV). The scatter of the experimental data does not allow us to determine an accurate $\nu_{\text {des }} / S$ value. Our saturated vapor density results agree well with the data reported in ref. [11], where the fluorescence light was analysed for saturated vapor density determination. The latent heat of evaporation $A$ is given by $A=N_{\mathrm{A}} Q_{\text {des }}=$ (1.3 \pm $0.2) \times 10^{5} \mathrm{~J} \mathrm{~mol}^{-1}$ (application of Clausius-Clapeyron equation [23], $N_{\mathrm{A}}$ is Avogadro constant).

\section{Conclusions}

The ionic dyes rhodamine $6 \mathrm{G}$ and rhodamine 19 have been investigated. Rhodamine $6 \mathrm{G}$ exists only in salt form and decomposes into rhodamine 19 before evaporating. For rhodamine 19 it is thought that only the unprotonated form is present in the vapor phase. The bulk rhodamine 19 decomposes and carbonizes rapidly above $280^{\circ} \mathrm{C}$. The vapor-phase rhodamine 19 decomposes into 2,7-dimethylrhodamine 110 above $320^{\circ} \mathrm{C}$. The absorption spectroscopic analysis of the rhodamine 19 vapor is limited to the temperature region around $\vartheta_{R} \approx 300 \mathrm{~K}$, where the vapor density is still very small and. long vapor cells are necessary for resonable absorption effects. But at this temperature region the absorption spectrum of rhodamine 19 could be measured and compared with solution spectra. The accumulated dye-flow measurement is very sensitive and allows the vapor density determination down to $200^{\circ} \mathrm{C}$. The latent heat of evaporation of rhodamine 19 could be calculated from the vapor pressure versus temperature.

The absorption spectroscopic behaviour of rhodamine $B$ [10] seems to be similar to that of rhodamine 19. As rhodamine 19 and rhodamine 110 , rhodamine $B$ has a protonated and an unprotonated form and it is thought that only the unprotonated (neutral zwitterionic) form exists in the vapor.

\section{References}

[1] F.P. Schäfer, ed., Topics in applied physics. Vol. 1. Dỵe lasers, 2nd Ed. (Springer, Berlin, 1977).

[2] N. Borisevich and V.A. Tolkatchev, Soviet Phys. Lisp. 25 (1982) 865 .

[3] Yu. Yu. Stoilov, Appl. Phys. B 33 (1984) 63.

[4] B. Steyer and F.P. Schäfer. Appl. Phys. 7 (1975) 113.

[5] N.G. Basov, O.A. Logunov, A.V. Stantsev, Yu.Yu. Stoilov and V.S. Zuev, J. Mol. Struct. 79 (1982) 119.

[6] J.P. Maier, A. Seilmeier. A. Laubereau and W. Kaiser. Chem. Phys. Letters 46 ( 1977 ) 527.

[7] J. Schmidt and A. Penzkofer, Chem. Phys. 117 (1987) 265

[8] V.F. Lukinykh, S.A. Myslivets, A.K. Popov and V.V. Slabko. Appl. Phys. B 38 (1985) 143.

[9] V.F. Lukinykh. S.A. Myslivets. A.K. Popov and V.V. Slabko. Soviet J. Quantum Electron. 16 (1986) 927.

[10] R. Pappalardo and S. Ahmed, J. Chem. Phys. 56 (1972) 5135.

[11] T. Sakurai and H.G. de Winter, J. Appl. Phys. 46 (1975) 875.

[12] A.T. Vartanyan, Zh. Fiz. Khim. 30 (1956) 1028.

[13] M.M. Asimov, E.V. Partonov and A.N. Rubinov: Opt. Spectry. 60 (1986) 799.

[14] K.H. Drexhage, Laser Focus $9 / 3$ (1973) 35.

[15] V. Huth, Dissertation, Universität-Gesamthochschule Siegen, Siegen, FRG (1986).

[16] K.H. Drexhage, in: Topics in applied physics, Vol. 1. Dye lasers, 2nd Ed., ed. F.P. Schäfer (Springer Verlag. Berlin. 1977).

[17] L.E. Jacobs and J.R. Platı. J. Chem. Phys. 16 (1948) 1137 
[18] W.R. Ware and P.T. Cunningham, J. Chem. Phys. 43 (1965) 3826.

[19] K.H. Hellwege and A.M. Hellwege, eds., Landolt-Bömstein, 6th Ed., Vol. 2, Part 8 (Springer, Berlin, 1962).

[20] D.E. Gray, ed., American Institute of Physics handbook, 3rd Ed. (McGraw-Hill, New York, 1972).

[2.1] M. Mataga and T. Kuivota, Molecular interactions and electronic spectra (McGraw-Hill, New York, 1972) ch. 8.
[22] J.D. Kelley and F.O. Rice, J. Chem. Phys. 68 (1964) 3794.

[23] P.W. Atkins. Physical chemistry, 2nd Ed. (Oxford Univ. Press, Oxford, 1982) p. 874.

[24] L. Eckertová, Physics of thin films, 2nd Ed. (Plenum Press, New York, 1986) p. 99. 